\title{
TITLE:
}

\section{Improved controllability of wet infiltration technique for fabrication of solid oxide fuel cell anodes}

\section{AUTHOR(S):}

Kishimoto, Masashi; Kawakami, Yuki; Otani, Yuki; Iwai, Hiroshi; Yoshida, Hideo

\section{CITATION:}

Kishimoto, Masashi ...[et al]. Improved controllability of wet infiltration technique for fabrication of solid oxide fuel cell anodes. Scripta Materialia 2017, 140: 5-8

\section{ISSUE DATE:}

2017-11

URL:

http://hdl.handle.net/2433/260570

\section{RIGHT:}

(c) 2017. This manuscript version is made available under the CC-BY-NC-ND 4.0 license http://creativecommons.org/licenses/by-nc-nd/4.0/.; この論文は出版社版でありません 。引用の際には出版社版をご確認ご利用ください。; This is not the published version. Please cite only the published version. 
Improved controllability of wet infiltration technique for fabrication of solid oxide fuel cell anodes

*Masashi Kishimoto, Yuki Kawakami, Yuki Otani, Hiroshi Iwai, Hideo Yoshida

Department of Aeronautics and Astronautics, Kyoto University, Kyoto 615-8540, Japan

Tel/Fax: +81-75-383-3652

E-mail: kishimoto.masashi.3m@kyoto-u.ac.jp

\begin{abstract}
$\mathrm{Ni} /$ yttria-stabilized zirconia anodes of solid oxide fuel cells are fabricated by a wet infiltration technique and the ability of the infiltration technique to control the anode microstructure is quantitatively demonstrated by a detailed three-dimensional microstructural analysis. The microstructural analysis reveals favorable aspects of the infiltrated anodes, such as larger triple-phase boundary density and sufficiently large pore size, and they are mostly unachievable by the conventional powder-mixing and sintering approaches. The improved controllability of the infiltration technique is expected to be useful to tailor porous microstructures to meet the multiple requirements for transport and electrochemical reactions within the anodes.
\end{abstract}

Keywords: infiltration; fuel cell materials; focused ion beam; porous material; microstructure designing 
It has become a common understanding that the performance and durability of solid oxide fuel cell (SOFC) electrodes are significantly influenced by their submicron-scale porous structures. For example, the phase connectivity and tortuosity factor determine the transport properties of active species in the electrodes, whereas the triple-phase boundary (TPB) and double-phase boundary (DPB) densities determine the electrochemical activity. The recent development of three-dimensional (3D) imaging techniques, such as focused ion beam scanning electron microscopy (FIB-SEM) and X-ray computed nanotomography, has enabled imaging of the complex 3D microstructure of electrodes with nanoscale resolution. This initiated discussion on the quantitative relationships between the electrode microstructure and performance. As a result of the extensive investigation of such relationships we can now begin to correlate the electrode performance with certain microstructural properties [1-4], and also understand the performance degradation of electrodes [5-7].

However, to improve the performance of SOFC electrodes, it is not sufficient to simply explain the electrode performance in terms of the electrode microstructures. The next step is to design microstructures that can meet a variety of requirements for the transport and electrochemical reactions within the electrodes and to propose an effective fabrication method that can actually realize such design-optimized electrode microstructures.

Currently, conventional SOFC electrodes are fabricated by mixing metal and ceramic particles, which is followed by sintering at a high temperature, typically around $1400^{\circ} \mathrm{C}$ for anode materials This high-temperature sintering is required to ensure the sufficient mechanical bonding of the ceramic 
particles and thus the structural robustness of the porous electrodes over long-term operation. However, at such a high temperature, the metal particles tend to agglomerate, reducing the volumetric density of the reaction sites $[8,9]$. Therefore, the conventional powder mixing and sintering processes may not be ideal for precisely controlling electrode microstructures.

From the viewpoint of controlling electrode microstructures, the nanoparticle infiltration technique is a promising alternative for the fabrication of SOFC electrodes $[10,11]$. An important feature of the infiltration technique is that the fabrication processes of the ceramic phase and the metal phase are separated; this may enable independent control of the fabrication parameters for each constituent phase, which can be a key to achieving design-optimized electrode microstructures. Although several studies have reported the improved electrochemical performance of infiltrated electrodes [12-27], the reason behind the improved performance has not been fully investigated in terms of electrode microstructures. Kishimoto et al. [28] first investigated the microstructure of an infiltrated Ni-GDC anode at $5 \mathrm{~nm}$ resolution using FIB-SEM and gave a quantitative explanation of the performance of infiltrated electrodes. It was revealed that the infiltrated anode had a smaller Ni particle size and a one order of magnitude larger TPB density than conventional anodes, which markedly improved the electrochemical activity. Also, by performing a numerical simulation, the ratedetermining process in infiltrated electrodes has been identified [29]. However, there has been few reports on the detailed microstructures of infiltrated Ni-YSZ anodes despite the fact that they are the most commonly used anode material in the commercial SOFC systems. Although several authors 
investigated the Ni-YSZ anode microstructures using conventional SEM [23-27], the information obtained were bound to be 2D, and did not give useful insights on the microstructures, such as the distribution of TPBs and the interconnectivity of the infiltrated Ni particles.

In this study, therefore, Ni-YSZ anodes are fabricated by the infiltration process, and their electrochemical and microstructural properties are analyzed using electrochemical impedance spectroscopy and FIB-SEM tomography, respectively. The quantified microstructural parameters are compared with those for a conventional composite Ni-YSZ anode to identify the structural characteristics that are unique to infiltrated electrodes.

Electrolyte-supported symmetric cells were used for the experiment. First, YSZ powder (YZ8Y, Tosoh Co.) was mixed with carbon black (SB220, Asahi Carbon Co.) as a pore former and ballmilled with ethanol for $12 \mathrm{~h}$. Ethanol was evaporated using a hot stirrer and the resultant powder was mixed with terpineol to form a slurry. The slurry was then painted on both sides of a YSZ disk electrolyte (24 mm diameter, $0.5 \mathrm{~mm}$ thick, Tosoh Co.), and calcined at $1450{ }^{\circ} \mathrm{C}$ for $4 \mathrm{~h}$. For the infiltration of nickel nanoparticles, precursor thermal decomposition was employed in this study, where nickel nitrate solution $(0.5 \mu \mathrm{L})$ was introduced into the scaffold and then thermally decomposed at $550{ }^{\circ} \mathrm{C}$ for $1 \mathrm{~h}$. The precursor solution used in this study was similar to that in ref. [30]: it was prepared by dissolving nickel nitrate hexahydrate (Nacalai Tesque) at its solubility limit ( $5 \mathrm{~mol} / \mathrm{L})$ at room temperature and then diluted with the same volume of ethanol (Nacalai Tesque) to decrease viscosity. The aim of this high concentration of nickel ion in the precursor compared with other studies 
(e.g. $0.3 \mathrm{~mol} / \mathrm{L}$ in [24], $0.1 \mathrm{~mol} / \mathrm{L}$ in [31]) is to infiltrate as much amount of nickel oxide as possible in

a single infiltration process. However, because the amount of nickel nanoparticles that could be introduced in a single infiltration process was still not sufficient for the anode structure to have a percolated network, the infiltration process was repeated multiple times. In this study samples infiltrated 10 and 20 times were analyzed.

To elucidate the advantages of the infiltration technique for electrode fabrication, an anode fabricated using the conventional powder mixing and sintering processes was used for comparison. Its solid volume fraction was adjusted to $\mathrm{Ni}: \mathrm{YSZ}=50: 50$ and the sintering temperature was $1400{ }^{\circ} \mathrm{C}$.

The electrochemical performance of the anodes was characterized in a symmetric electrode setup. A platinum mesh was used for current collection. The cells were held with an alumina fixture and their temperature was controlled by an electric furnace. 3\% humidified hydrogen was supplied to the cells with a constant flow rate of $100 \mathrm{~mL} / \mathrm{min}$ on both sides of the cells. Humidification was performed using a bubbler, whose temperature was precisely controlled by a constant temperature bath. Electrochemical impedance measurement was conducted with a four-electrode configuration using a Solartron 1286 electrochemical interface and a Solartron 1255 frequency analyzer.

The 3D microstructure of the tested Ni-YSZ anodes was imaged using FIB-SEM to evaluate their microstructural parameters. After the electrochemical measurements, the Ni-YSZ anodes were cooled to room temperature in nitrogen, and impregnated with epoxy resin (Specifix 20, Struers) under vacuum to allow easier identification of the pore phase in the subsequent FIB-SEM imaging. The 3D 
microstructure of the anodes was imaged using an NVision40 (Zeiss) FIB-SEM system. The in-lens secondary electron detector was used to distinguish the two solid phases in the SEM images. Regions were selected for microstructural analysis and subjected to the following image processing: (i) alignment of the stack images using the least-squares method, (ii) noise reduction using an edgepreserving smoothing filter and (iii) segmentation using a 2D histogram segmentation algorithm based on the watershed algorithm followed by manual correction. As a result, the 3D porous microstructures were virtually reconstructed, from which microstructural parameters, such as the phase volume fraction, tortuosity factor, phase size and TPB density, were quantified. Volume fraction was quantified on the basis of the voxel counting method; tortuosity factor was quantified by random walk simulation [1, 32]; phase size was quantified with the 3D line-intercept method [33, 34]; and TPB density was quantified using the volume expansion method [1]. Commercial image processing software (Avizo, Thermo Fisher Scientific) was used for the alignment, segmentation, 3D reconstruction and part of the quantification of the microstructural parameters.

It was suggested in ref. [29] that the pore size in anodes after Ni infiltration should be no less than ca. $1 \mu \mathrm{m}$ to avoid Knudsen diffusion becoming involved in the gas diffusion process. Therefore, as a preliminary analysis, we investigated the effect of the amount of pore former on the resulting porosity and pore size in the scaffold structures. Therefore, YSZ scaffold structures with different porosities were first fabricated by changing the weight ratio of carbon black to the YSZ ink, i.e., 20, 30, 40 and 50 wt.\%. The scaffold structures before nickel infiltration were analyzed by FIB-SEM and 
their porosity and pore size were quantified with the same procedures explained above. Fig. 1 shows the porosity and pore size in the scaffold as a function of the amount of added pore former. It was found that the porosity increased with increasing amount of pore former. According to this result, the weight ratio of carbon black to YSZ powder in the test cells was determined as 50:50, which gave ca. $60 \%$ porosity and ca. $2.6 \mu \mathrm{m}$ pore size in the YSZ scaffold structure before infiltration.

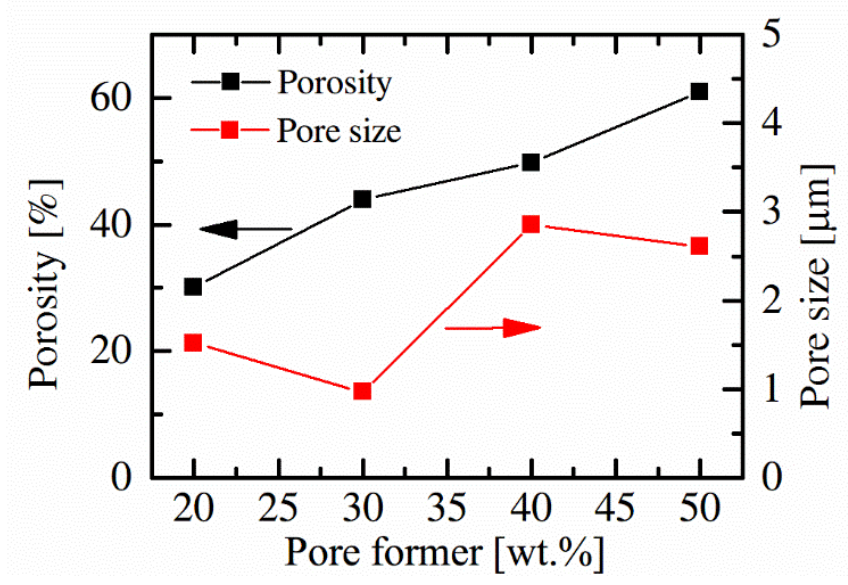

Fig. 1 Effect of the amount of pore former on the porosity and pore size in the scaffold.

Fig. 2 shows the results of the electrochemical impedance analysis of the infiltrated and conventional anodes at $800{ }^{\circ} \mathrm{C}$. Bulk electrolyte resistances were removed from the spectra for easier comparison of the polarization resistances. As clearly shown, the polarization resistance of the infiltrated anodes was reduced as the infiltration time, and the anode with 20 time infiltration exhibited significantly less polarization resistance than the conventional anode. 


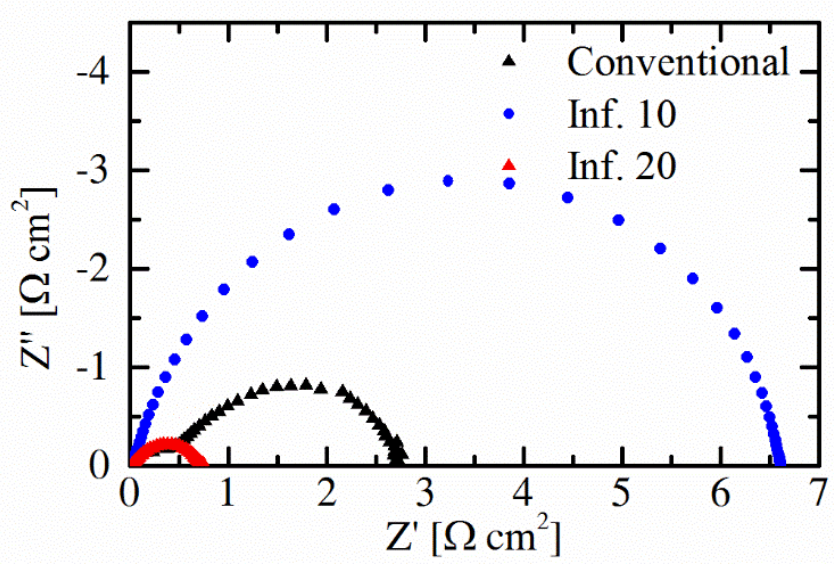

Fig. 2 Result of electrochemical impedance analysis at $800{ }^{\circ} \mathrm{C}$ with $3 \%$ humidified hydrogen.

To determine the reason for this superior performance of the anode with 20 time infiltration, the 3D microstructures of the anodes were characterized by FIB-SEM and reconstructed as shown in Fig. 3. The images on the top (Fig. 3(a)) show the composite anode microstructures consisting of Ni and YSZ particles, whereas those on the middle (Fig. 3(b)) show the distribution of the Ni particles with the YSZ particles shown in transparent gray. The Ni particles shown in red are the isolated particles that do not contribute to the electronic conduction and hence the TPBs formed by those particles do not act as effective reaction sites. The images on the bottom (Fig. 3(c)) show the distribution of the TPB lines within the anodes, where the effective TPBs are shown in blue and the isolated and unknown TPBs [4] in red. Clearly, the Ni particles in the infiltrated anodes appears to have a smaller characteristic scale, which indicates noticeable differences in the porous microstructure between the infiltrated and conventional anodes. Also the infiltrated anodes have more reaction sites than the conventional anode, although those in the anode with 10 time infiltration are partly inactive because large part of the $\mathrm{Ni}$ 
phase is isolated. To explain these differences in a quantitative manner, these porous anode microstructures were analyzed using the microstructural parameters.

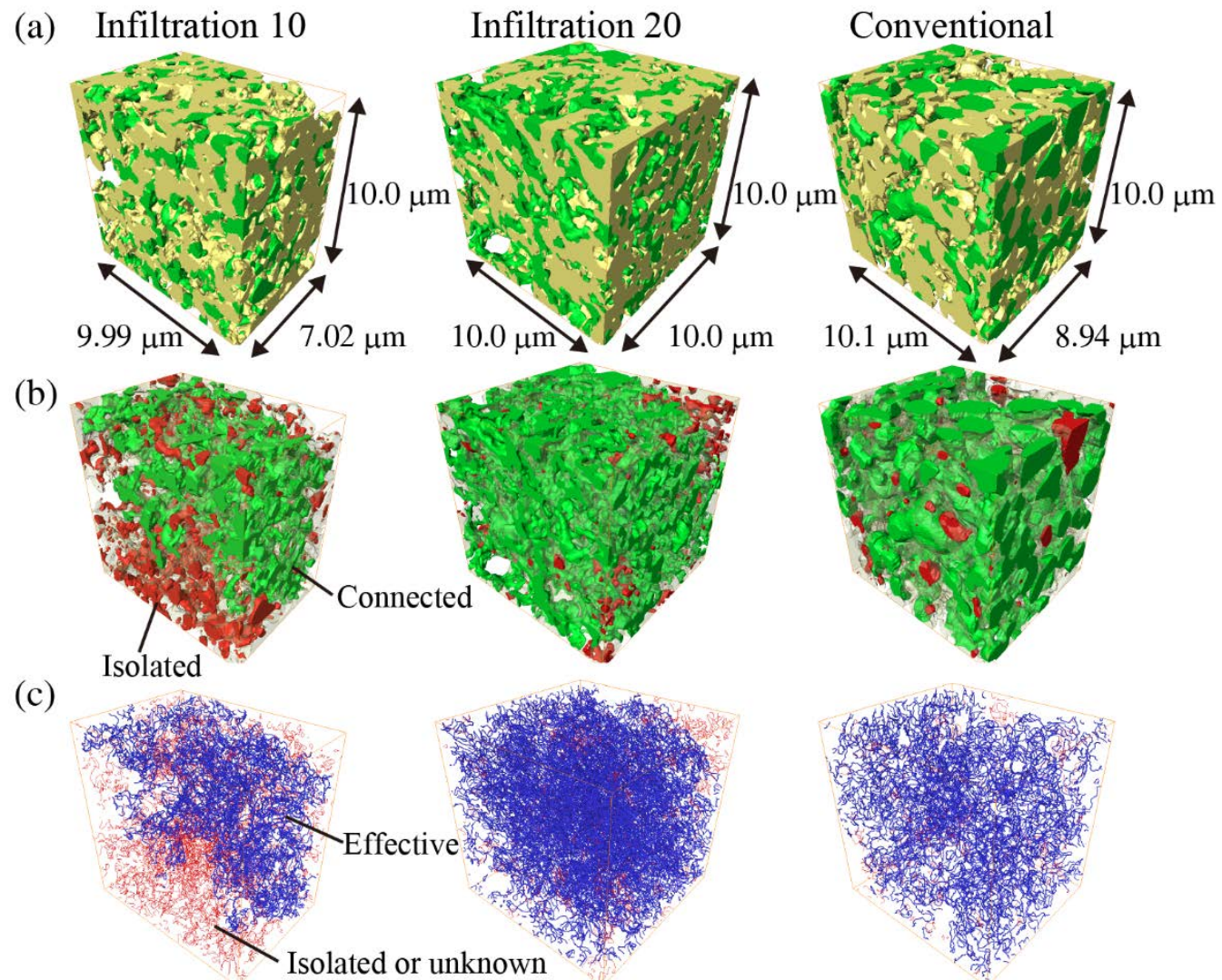

Fig. 3 Reconstructed microstructures. (a) Ni-YSZ (green: Ni, yellow: YSZ). (b) Ni particles (green: connected Ni, red: isolated Ni). (c) TPB distribution (blue: effective TPBs, red: isolated or unknown TPBs).

As shown in Table 1, there are several interesting characteristics in the infiltrated anodes, and they are mostly advantageous in terms of anode electrochemical performance. 
Table 1 Microstructural parameters.

\begin{tabular}{lllll}
\hline Parameter & & Infiltration 10 & Infiltration 20 & Conventional \\
\hline Sample size $\left[\mu \mathrm{m}^{3}\right]$ & & $7.02 \times 10.0 \times 9.99$ & $10.0 \times 10.0 \times 10.0$ & $8.94 \times 10.0 \times 10.1$ \\
Voxel size $\left[\mathrm{nm}^{3}\right]$ & & $29.5 \times 29.5 \times 58.4$ & $39.7 \times 39.7 \times 67.3$ & $34.4 \times 34.4 \times 90.5$ \\
\hline Volume fraction $[\%]$ & $\mathrm{Ni}$ & 13.4 & 20.9 & 32.3 \\
& YSZ & 42.7 & 47.4 & 27.5 \\
& Pore & 43.9 & 31.7 & 40.2 \\
\hline Connectivity $[\%]$ & $\mathrm{Ni}$ & 61.2 & 95.9 & 96.5 \\
& YSZ & 99.8 & 99.8 & 97.6 \\
& Pore & 99.9 & 96.7 & 99.6 \\
\hline Phase size $[\mu \mathrm{m}]$ & Ni & 0.51 & 0.57 & 1.36 \\
& YSZ & 1.21 & 1.20 & 0.81 \\
& Pore & 1.84 & 1.18 & 1.39 \\
\hline Tortuosity factor $[-]$ & Ni & 30.0 & 6.00 & 5.26 \\
& YSZ & 2.42 & 2.30 & 5.94 \\
& Pore & 2.81 & 7.50 & 2.53 \\
\hline TPB density $\left[\mu \mathrm{m} / \mu \mathrm{m}^{3}\right]$ & Effective/Total & $2.70 / 5.88$ & $6.83 / 7.37$ & 3.22 / 3.50 \\
\hline
\end{tabular}

(i) The volume fraction of the Ni phase is smaller in the infiltrated anodes, and they are even smaller than the conventional percolation threshold ( 30 \%) [35]. Nevertheless, the connectivity of the $\mathrm{Ni}$ phase is still maintained, particularly in the anode with 20 time infiltration. This is because the $\mathrm{Ni}$ phase was formed on the surface of the YSZ scaffold so that the volume of the Ni particles was effectively used to form the percolated cluster. This is one of the improvements from the previously reported infiltrated Ni-GDC anode, where the nickel phase was not fully percolated and therefore the electronic conduction in the anode relied on the mixed conductivity of the GDC phase [28]. This improvement is attributed to the optimization of the scaffold porosity and pore size.

(ii) The tortuosity factor of the YSZ phase was decreased in the infiltrated anodes because of the 
higher YSZ volume fraction and large particle size. According to the literature [28, 32], the sensitivity of the anode performance to the YSZ tortuosity factor is one of the greatest among the various microstructural parameters, because of the higher transport resistance of the YSZ phase. Therefore, the reduction in the YSZ tortuosity factor is also emphasized as an improvement in the anode microstructure. This will reduce the resistance associated with the oxide ion conduction within the anode and enlarge the active reaction region from the anode-electrolyte interface towards the anode surface [36].

(iii) The average particle size of the Ni phase is about one-third of that in the conventional anode. This is mainly because the nickel phase was not subjected to the high-temperature sintering typically carried out in the conventional fabrication process. The smaller Ni particle size results in a significant increase in the total TPB density, which supports the findings reported in [28]. This is considered to be a direct reason for the reduced polarization resistance of the anode with 20 time infiltration. The total TPB density in the anode with 10 time infiltration is also higher than that in the conventional anode; however, the effective TPB density is less than that in the conventional anode because nearly half of the TPBs are categorized as isolated or unknown owing to the insufficient connectivity of the Ni phase. As in the ref. [4], when the connectivity of the Ni phase is insufficient, the effective TPBs tend to be distributed only in the vicinity of the anode surface instead of the anode-electrolyte interface, which increases resistance of the anode. These can explain the trend of the anode resistance observed in Fig. 2. 
(iv) The average pore size in the infiltrated anodes was comparable to that in the conventional anode. According to the literature [29], if the pore size is submicron, Knudsen diffusion becomes involved in the gas diffusion process and significantly increases the gas diffusion resistance. In this study, it was confirmed that adding pore former is effective for increasing the pore size and avoiding Knudsen diffusion in the gas diffusion in the porous anodes. The increased pore tortuosity factor does not adversely affect the anode performance because the molecular diffusion is still sufficiently fast.

As described above, a favorable anode microstructure was successfully fabricated by the infiltration method based on precursor thermal decomposition. While retaining the advantages of the method achieved in the previous report [28], the issues that existed in the infiltrated Ni-GDC anode were resolved by tuning the fabrication processes. Some of the characteristics of the infiltrated anodes are unachievable by conventional fabrication processes, such as a smaller Ni particle size and better Ni percolation with a smaller volume fraction. This study quantitatively shows the ability of the infiltration technique to control anode microstructures and to tailor them to achieve improved transport and electrochemical properties.

As shown in this study and in other previous works, the infiltration technique has great potential for improving electrochemical performance of the SOFC electrodes and lowering their operation temperature. However, the infiltration process employed in this work is, similar to most of the previous works, time-consuming and energetically inefficient because it requires multiple infiltration with heating up and cooling down cycles. To scale up this technique towards the industrial level, infiltration 
should be conducted in a continuous manner without multiple heating up and cooling down cycles. In this sense, the spray pyrolysis technique demonstrated in dos Santos-Gomez et al. [37] may be one of the candidates. Further investigation on the infiltration technique to realize its implementation into industrial-scale fabrication will be required and one of our future works.

\section{Acknowledgment}

This work was supported by JSPS KAKENHI grant number 15H06321. The authors would like to thank Asuto Masuyama for providing impedance and microstructural data of the conventional Ni-YSZ anode. 


\section{References}

[1] H. Iwai, N. Shikazono, T. Matsui, H. Teshima, M. Kishimoto, R. Kishida, D. Hayashi, K. Matsuzaki, D. Kanno, M. Saito, H. Muroyama, K. Eguchi, N. Kasagi, H. Yoshida, Journal of Power Sources, 195 (2010) 955-961.

[2] N. Vivet, S. Chupin, E. Estrade, A. Richard, S. Bonnamy, D. Rochais, E. Bruneton, Journal of Power Sources, 196 (2011) 9989-9997.

[3] M. Kishimoto, H. Iwai, M. Saito, H. Yoshida, Journal of Power Sources, 196 (2011) 4555-4563.

[4] M. Kishimoto, K. Miyawaki, H. Iwai, M. Saito, H. Yoshida, Fuel Cells, 13 (2013) 476-486.

[5] K. Eguchi, N. Kamiuchi, J.Y. Kim, H. Muroyama, T. Matsui, M. Kishimoto, M. Saito, H. Iwai, H. Yoshida, N. Shikazono, N. Kasagi, J. Akikusa, H. Eto, D. Ueno, M. Kawano, T. Inagaki, Fuel Cells, 12 (2012) 537-542.

[6] G. Brus, K. Miyoshi, H. Iwai, M. Saito, H. Yoshida, International Journal of Hydrogen Energy, 40 (2015) 6927-6934.

[7] G. Brus, H. Iwai, A. Sciazko, M. Saito, H. Yoshida, J.S. Szmyd, Journal of Power Sources, 288 (2015) 199-205.

[8] S. Hara, A. Ohi, N. Shikazono, Journal of Power Sources, 276 (2015) 105-112.

[9] Z. Jiao, G. Lee, N. Shikazono, N. Kasagi, Journal of the Electrochemical Society, 159 (2012) F278F286.

[10] S.P. Jiang, Materials Science and Engineering: A, 418 (2006) 199-210.

[11] S.P. Jiang, International Journal of Hydrogen Energy, 37 (2012) 449-470.

[12] J.M. Vohs, R.J. Gorte, Advanced Materials, 21 (2009) 943-956.

[13] B. Timurkutluk, C. Timurkutluk, M.D. Mat, Y. Kaplan, International Journal of Energy Research, 35 (2011) 1048-1055.

[14] X. Li, N. Xu, X. Zhao, K. Huang, Journal of Power Sources, 199 (2012) 132-137.

[15] Z. Liu, B. Liu, D. Ding, M. Liu, F. Chen, C. Xia, Journal of Power Sources, 237 (2013) 243-259.

[16] K. Tamm, R. Küngas, R.J. Gorte, E. Lust, Electrochimica Acta, 106 (2013) 398-405. 
[17] A. Torabi, T.H. Etsell, Journal of Power Sources, 225 (2013) 51-59.

[18] X. Meng, D. Han, H. Wu, J. Li, Z. Zhan, Journal of Power Sources, 246 (2014) 906-911.

[19] S.-I. Lee, J. Kim, J.-W. Son, J.-H. Lee, B.-K. Kim, H.-J. Je, H.-W. Lee, H. Song, K.J. Yoon, Journal of Power Sources, 250 (2014) 15-20.

[20] P. Keyvanfar, V. Birss, Journal of the Electrochemical Society, 161 (2014) F660-F667.

[21] F.S. Torknik, A. Maghsoudipour, M. Keyanpour-Rad, G.M. Choi, S.H. Oh, G.-Y. Shin, Ceramics International, 40 (2014) 12299-12312.

[22] R. Kiebach, P. Zielke, J.V.T. Høgh, K. Thydén, H.J. Wang, R. Barford, P.V. Hendriksen, Fuel Cells, 16 (2016) 80-88.

[23] J. Qiao, K. Sun, N. Zhang, B. Sun, J. Kong, D. Zhou, Journal of Power Sources, 169 (2007) 253258.

[24] A.N. Busawon, D. Sarantaridis, A. Atkinson, Electrochemical and Solid-State Letters, 11 (2008) B186.

[25] T. Klemensø, K. Thydén, M. Chen, H.-J. Wang, Journal of Power Sources, 195 (2010) 7295-7301. [26] A. Buyukaksoy, V. Petrovsky, F. Dogan, Journal of the Electrochemical Society, 159 (2012) B232B234.

[27] A. Buyukaksoy, S.P. Kammampata, V.I. Birss, Journal of Power Sources, 287 (2015) 349-358.

[28] M. Kishimoto, M. Lomberg, E. Ruiz-Trejo, N.P. Brandon, Journal of Power Sources, 266 (2014) 291-295.

[29] M. Kishimoto, M. Lomberg, E. Ruiz-Trejo, N.P. Brandon, Electrochimica Acta, 190 (2016) 178185.

[30] M. Lomberg, E. Ruiz-Trejo, G. Offer, N.P. Brandon, Journal of the Electrochemical Society, 161 (2014) F899-F905.

[31] J. Karczewski, B. Bochentyn, S. Molin, M. Gazda, P. Jasinski, B. Kusz, Solid State Ionics, 221 (2012) 11-14.

[32] M. Kishimoto, H. Iwai, M. Saito, H. Yoshida, in: 14th International Heat Transfer Conference, Washington D.C., 2010, pp. 37-46.

[33] M. Kishimoto, H. Iwai, M. Saito, H. Yoshida, Journal of the Electrochemical Society, 159 (2012) 
B315-B323.

[34] M. Kishimoto, H. Iwai, K. Miyawaki, M. Saito, H. Yoshida, Journal of Power Sources, 223 (2013) 268-276.

[35] D. Chen, Z. Lin, H. Zhu, R.J. Kee, Journal of Power Sources, 191 (2009) 240-252.

[36] K. Miyawaki, M. Kishimoto, H. Iwai, M. Saito, H. Yoshida, Journal of Power Sources, 267 (2014) 503-514.

[37] L. dos Santos-Gómez, J.M. Porras-Vázquez, F. Martín, J.R. Ramos-Barrado, E.R. Losilla, D. Marrero-López, Journal of Power Sources, 319 (2016) 48-55. 


\section{Figure captions}

Fig. 1 Effect of the amount of pore former on the porosity and pore size in the scaffold.

Fig. 2 Result of electrochemical impedance analysis at $800{ }^{\circ} \mathrm{C}$ with $3 \%$ humidified hydrogen.

Fig. 3 Reconstructed microstructures. (a) Ni-YSZ (green: Ni, yellow: YSZ). (b) Ni particles (green: connected $\mathrm{Ni}$, red: isolated $\mathrm{Ni}$ ). (c) TPB distribution (blue: effective TPBs, red: isolated or unknown TPBs).

\section{Table captions}

Table 1 Microstructural parameters. 